\title{
Damage Evolution and Failure Mechanisms in Additively Manufactured Stainless Steel
}

Holly D. Carlton ${ }^{* 1}$, Abdel Haboub ${ }^{3}$, Gilbert F. Gallegos ${ }^{1}$, Dilworth Y. Parkinson², and Alastair A. MacDowell ${ }^{2}$

${ }^{1}$ Materials Engineering Division, Lawrence Livermore National Laboratory, 7000 East Avenue, Livermore, CA 94550, USA

${ }^{2}$ Advanced Light Source, Lawrence Berkeley National Laboratory, 1 Cyclotron Rd, Berkeley, CA 94720, USA

${ }^{3}$ Lincoln University, Life and Physical Sciences Department, Jefferson City, MO 65101, USA

\begin{abstract}
In situ tensile tests were performed on additively manufactured austenitic stainless steel to track damage evolution within the material. For these experiments Synchrotron Radiation micro-Tomography was used to measure three-dimensional pore volume, distribution, and morphology in stainless steel at the micrometer length-scale while tensile loading was applied. The results showed that porosity distribution played a larger role in affecting the fracture mechanisms than measured bulk density.
\end{abstract}

*Corresponding author: Holly D. (formerly Barth) Carlton, carlton4@llnl.gov, +1-925-422-2765, 7000 East Ave, Livermore, CA 94550 
Specifically, additively manufactured stainless steel specimens with large inhomogeneous void distributions displayed a flaw-dominated failure where cracks were shown to initiate at pre-existing voids, while annealed additively manufactured stainless steel specimens, which contained low porosity and randomly distributed pores, displayed fracture mechanisms that closely resembled wrought metal.

Keywords: Additive manufacturing; Selective laser melting; Stainless steel; Porosity distribution; Synchrotron Radiation micro-Tomography

\section{Introduction}

Additive manufacturing (AM), such as selective laser melting (SLM), has emerged as a useful process for producing metal parts with complex geometries quickly and efficiently. Recently a big emphasis has been placed on using AM to manufacture parts that contain multi or functionally graded materials [1]. These parts are designed to have specific density, microstructure, and mechanical properties. However, SLM produced metals are not fully understood, especially with respect to unwanted defects introduced during the SLM process. Some processing related defects are due to issues such as lack of fusion and gas porosity, which are difficult to control and can yield parts with a 
variety of densities and void distributions. Recent work by King et al., [2] showed that the SLM process can create keyholes and localized incomplete melting based on the selected laser parameters, which leads to the presence of voids in the processed material. Unwanted defects, introduced during the SLM process, are detrimental to the mechanical performance of the metal part [3-5].

316L stainless steel (SS) is an austenitic grade SS that is commonly produced using SLM. There is a wide range of applications for 316L SS parts that span many industries, such as biomedical, automotive, aerospace, and oil and gas. 316L SS is known for its mechanical properties, specifically high strength and ductility, and its high corrosion resistance. The SLM process has many parameter inputs that are selected based on the type of material being built. Some of the major input parameters include laser beam scanning speed and power. Different parameters have been investigated to try to identify AM settings that produce full density parts [6-8]. In the scientific community there has been a large effort to evaluate the mechanical properties of metals built with different parameters and build orientations [5, 6, 9-11]. During several studies [5, 12, 13] it was shown that the SLM processing parameters do influence the porosity and quality of SS. 
In order for $\mathrm{AM}$ parts to replace conventionally produced metals the porosity distribution, and the effects porosity has on the mechanical performance of AM SS needs to be fully examined. The ability to control porosity also impacts the development of lightweighting structural materials, where AM is being utilized to build new lightweight lattice structures [14-16] and biomaterials [17]. For these types of applications there is a need to make AM metals that are both low density and high strength with a high level of control.

Synchrotron Radiation x-ray micro-Tomography $(\mathrm{SR} \mu \mathrm{T})$ is a powerful high-resolution 3D imaging technique used to visualize and quantify porosity at the micron-scale. In situ mechanical tests are currently being performed on metals at different synchrotron sources around the world [18-20]. Several studies have used tensile testing during X-ray tomography to map void growth in heterogeneous ductile materials, such as dual phase steels [19] and Ti6Al4V [18]. This information has been used to inform finite element procedures and algorithms for tracking damage. At the Advanced Light Source's (ALS, LBNL, Berkeley, CA) tomography beamline (8.3.2) there is a dedicated custom built mechanical testing device developed by Haboub et al. [21] and Bale et al. [22]. 
For this study crack initiation and damage evolution in SS, both AM and wrought, were investigated using in situ tensile testing coupled with SR $\mu \mathrm{T}$. AM SS specimens tested here were subject to parameters producing different porosity distributions and exposed to different heat treatments. The information obtained was used to compare AM SS fracture mechanisms with more conventionally processed SS.

\section{Experimental Methods}

\subsection{Additive Manufacturing Process}

AM SS specimens, used in this study, were built using a Concept Laser M2 powder-bed fusion additive manufacturing machine using CL 20ES (316L) powder, supplied by Concept Laser, $\mathrm{GmbH}$ (Germany). Concept laser $\mathrm{GmbH}$ uses a laser cusing process during the SLM to fuse each powder bed layer. The term cusing refers to a feature that 
is a stochastic exposure strategy based on the island principle. Each layer of the required cross-section is divided into segments called "islands," this strategy reduces thermal gradients on the surface with the goal of reducing stresses within the component [23]. The CL20 powder contains spherical form particles ranging from 25-53 $\mu \mathrm{m}$. Detailed characterization of the powder can be found here [24]. The AM SS tensile specimen were machined from bulk AM material. Metallography was performed on each sample group to characterize the microstructure.

\subsection{Materials}

Certified 316L SS was used in this study as a reference material and is referred to as the "wrought" condition for this paper. The wrought SS was hot rolled, annealed and rough turned. Table 1 reports the tensile properties for the wrought material.

For the two AM SS groups different processing parameters were selected which resulted in sample groups with two different densities. The only difference between the two parameter sets was the laser beam scan speed, which is the speed at which the laser rasters over the powder bed. The scan speed was selected as 400 and $222 \mathrm{~mm} / \mathrm{sec}$ for the high porosity and low porosity groups, respectively. For both groups the main 
parameters, layer thickness, a1 (spacing between scan vectors), and laser power, were selected as $30 \mu \mathrm{m}, 0.7$ and $100 \mathrm{~W}$, respectively. It should be noted that on this machine a $100 \mathrm{~W}$ laser power setting was evaluated and found to correspond to an actual power of $85 \mathrm{~W}$. The untreated AM 316L SS processed condition is referred to as the "as-built" condition.

Several of the AM SS specimens from both porosity groups were selected for an annealing heat treatment, which consisted of heating the samples to $1095^{\circ} \mathrm{C}$ and holding there for 1 hour in a vacuum furnace. Then, in order to cool fast enough to avoid precipitates the specimens were exposed to Argon gas until it reached $400^{\circ} \mathrm{C}$. The AM SS heat treated as described above is referred to as the "annealed" condition.

An AM SS specimen was selected for a stress relieving heat treatment, which consisted of heating up the sample to $700^{\circ} \mathrm{C}$ and holding there for 1 hour in a vacuum furnace [25]. This sample was used for hardness tests, along with an as-built and annealed sample, in order to measure the contribution that residual stresses have on the mechanical properties. 


\subsection{Tomography Experiment}

The tensile testing specimen geometry and the in situ mechanical testing device at the ALS was adapted to perform these situ tensile tests on AM SS. The tensile specimen was designed with a taper, so that the failure was more likely to occur within the small field of view. The tomographic imaging was performed at beamline 8.3.2 at the Advanced Light Source (Lawrence Berkeley National Laboratory, Berkeley, CA, USA) in white-light mode. The experimental setup was similar to standard tomographic procedures [26] where the specimen was rotated in an X-ray beam and the transmitted radiographic projections were imaged via a scintillator, magnifying lens, and a digital camera. For this experiment, the effective voxel size was $1.3 \mu \mathrm{m}$. Reconstructed images were obtained via a filtered back-projection algorithm using the software package Octopus [27]. Three-dimensional visualization, segmentation, and quantification of the void distribution was performed using Avizo ${ }^{\mathrm{TM}}$ software [28].

During tensile testing each specimen was loaded using displacement control at a quasistatic rate. The specimen was held at specified loads along the load-displacement curve during each scan, which lasted 3-5 minutes. Figure 1 shows a representative load-time 
graph. The inset plot in Figure 1 shows the resulting load versus displacement graph.

There was some relaxation observed during each scan.

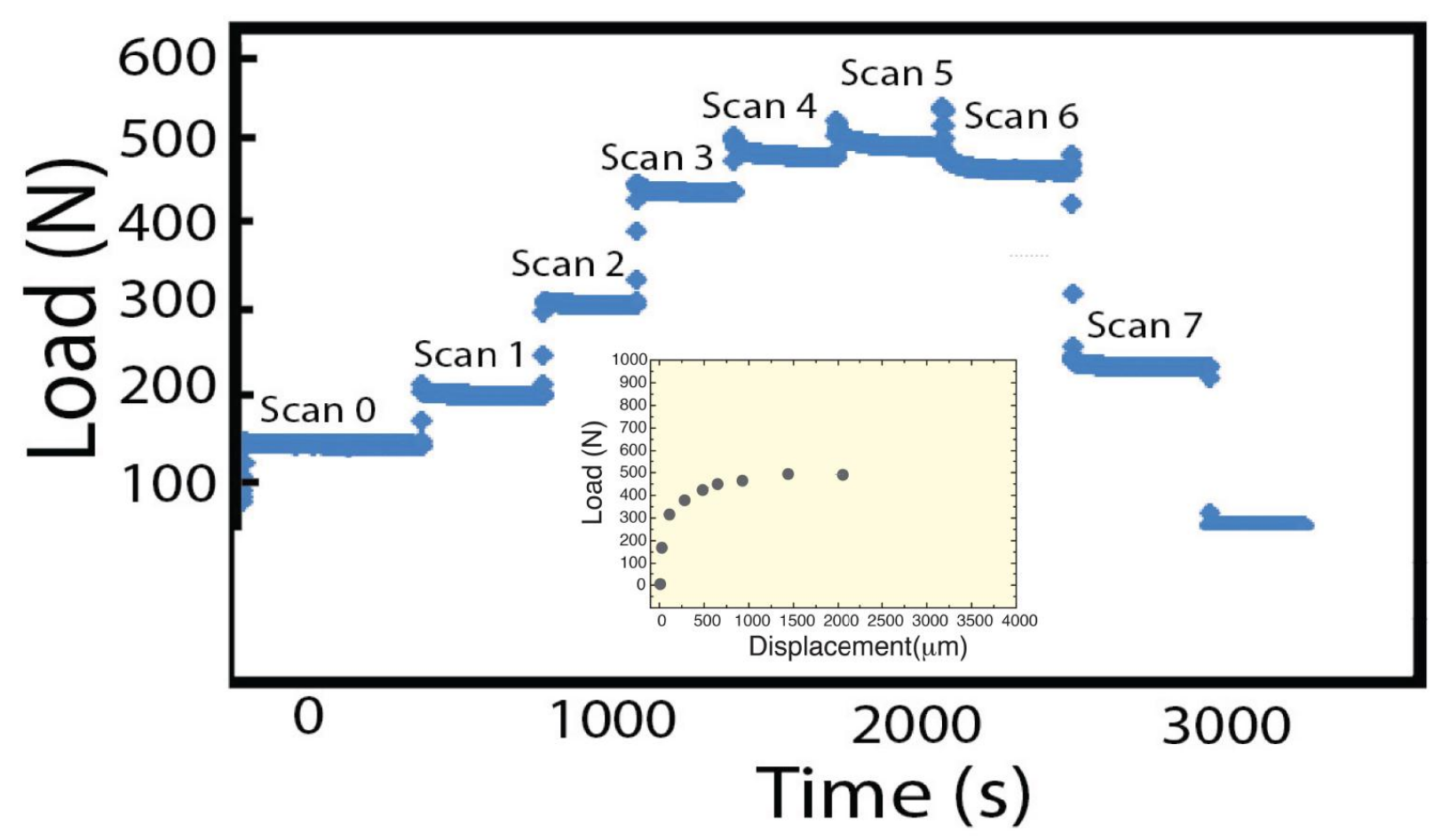

Figure 1. Results from in situ tensile tests performed on SS. This figure shows a representative force versus time graph from an in situ tensile test on a SS specimen. Each scan number designates a tomographic data set. There is some load relaxation observed during the scans, especially after the sample starts to plastically deform. The inset plot shows the resulting load versus displacement for the representative SS specimen tested. 


\section{Results \& Discussion}

\subsection{Mechanical Properties}

Prior to in situ tensile testing bulk mechanical properties were evaluated for AM SS using larger scale tensile specimens. The specimens were machined to have a gauge diameter of $6.35 \mathrm{~mm}$. Here the AM SS specimens were tested in the annealed and asbuilt conditions. Figure 2 shows representative engineering stress-strain curves for an annealed and as-built AM SS tensile specimen. Table 1 reports the results (ultimate tensile strength, yield strength ( $0.2 \%$ offset), elongation at failure and reduction of area (RA)) from the tensile tests. 


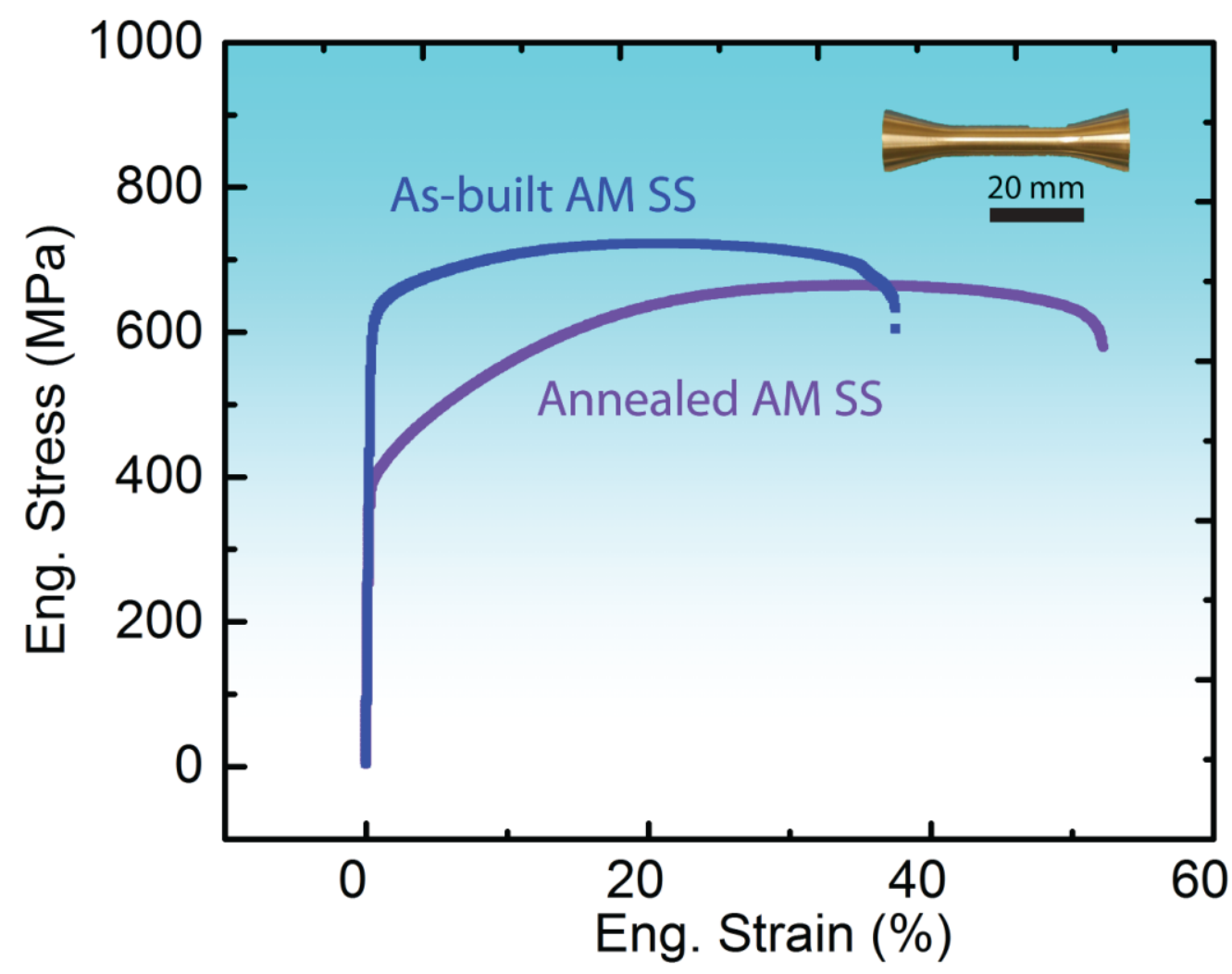

Figure 2. Bulk mechanical properties of SS. Representative engineering stress-strain curves for tensile tests performed on specimen with a $6.35 \mathrm{~mm}$ gauge diameter.

The yield strength for the annealed AM SS specimens was found to be $\sim 60 \%$ of the measured yield strength for the as-built AM SS condition. While the ultimate tensile strength was slightly lower for the annealed group, the elongation and RA were both higher, indicating that the annealing was effective at increasing the ductility of the AM SS specimens. 
Table 1. Results from tensile tests performed on annealed and as-built AM SS specimens with a gauge diameter of $6.35 \mathrm{~mm}$. Here the ultimate tensile strength (UTS), yield strength (YS), elongation to failure, and reduction of area (RA), and number of specimen tested (n) are reported. The SLM laser parameters were selected to yield high density AM SS specimens. Immersion density results determined that the overall porosity for the AM SS samples was $1.2+/-0.3 \%$, while wrought specimens had $0.1 \%$ porosity.

\begin{tabular}{|c|cccc|}
\hline & UTS & YS & Elongation & RA \\
$\begin{array}{c}\text { AM SS } \\
\text { Condition }\end{array}$ & (MPa) & (MPa) & (\%) & (\%) \\
\hline $\begin{array}{c}\text { As-built } \\
(\mathrm{n}=3)\end{array}$ & $705+/-15$ & $590+/-17$ & $44+/-7$ & $53+/-10$ \\
\hline $\begin{array}{c}\text { Annealed } \\
(\mathrm{n}=8)\end{array}$ & $635+/-17$ & $375+/-11$ & \\
\hline \\
\hline
\end{tabular}

*SST material was certified by Dunkirk Specialty Steel, LLC. The mechanical properties shown here were reported by the company that provided the SS material.

During the SLM build process residual stresses develop within the material [29]. In order to investigate the effects that residual stresses have on yield strength of the 
material, which was shown to decrease for the annealed condition, hardness tests were performed on as-built, stress relieved, and annealed AM SS, and the results are reported in Table 2. The stress relieved specimens were exposed to a $700^{\circ} \mathrm{C}$ heat treatment in order to relieve any residual stresses imposed from the build process while still maintaining a microstructure that closely resembles the as-built condition. The results from the Vicker's hardness (HV) tests determined that, when compared to the as-built group, the stress relieved specimen's hardness values decreased on average by $25 \mathrm{HV}$, while the annealed specimen's hardness values decreased on average by $125 \mathrm{HV}$. Therefore the decrease in yield strength seen in the annealed condition must be related to other factors, such as microstructure, rather than just a result of the subsequent annealing heat treatment relieving the residual stresses in the material.

Table 2. Results from Vickers hardness tests performed on AM SS under three different treatment conditions. The micro-hardness tests were performed using a $100 \mathrm{gF}$ load.

\begin{tabular}{|l|ccc|}
\hline & As-built & Stress Relieved & Annealed \\
\hline Vickers Hardness Values & & & \\
\hline Average & 325 & 300 & 200 \\
\hline Standard Deviation & 15 & 15 & 5 \\
\hline Max & 350 & 320 & 210 \\
\hline
\end{tabular}




\begin{tabular}{|l|lll|}
\hline Min & 305 & 275 & 190 \\
\hline
\end{tabular}

\subsection{Damage Evolution E Fracture Mechanisms in AM SS}

In order to get a baseline to quantify changes in void distribution, RA, and growth and coalescence of voids in the SS specimens, the static (sample under no load) tomography data set was analyzed. Figure 3 shows representative 3D pore distributions for wrought, low porosity AM, and high porosity AM SS specimens, where the average volume percentage of porosity was measured as $<0.1,0.1,2.2 \%$, and the largest $\%$ was measured in the $\mathrm{z}$-axis as $0.05,1,17 \%$, for each group respectively. As specified earlier the high and low porosity groups were built with different laser parameters selected from Archimedes immersion density measurements. Qualitatively the high porosity group appeared to have a noticeably larger and more inhomogeneous void distribution than the low porosity AM and wrought specimens. The average porosity for the high porosity group was determined to be $2.2 \%$, however when you look at the $3 \mathrm{D}$ porosity distribution in Figure $3 b$ the porosity appeared to be much larger than $\sim 2.2 \%$. 
a)



Figure 3. Porosity distribution in AM SS. (a) shows a representative 3D void distribution for wrought, low porosity AM, and high porosity AM, stainless steel tensile specimens. The AM SS specimens were built with $100 \mathrm{~W}$ power, and speeds of 222 and $400 \mathrm{~mm} / \mathrm{s}$ for the low and high porosity groups, respectively. The plot (b) shows the porosity versus distance in direction of the tensile loading and the z-axis depicted in (a). This plot examines how porosity varies throughout the samples shown in (a). Even though the overall average porosity is $\sim 2.2 \%$ for the high porosity group (green line), there are regions within the specimen where porosity reaches $17 \%$. The low porosity sample (blue line) only reaches a maximum porosity of $<\sim 2 \%$. 
To further evaluate the high porosity specimen the porosity distribution was quantified along tensile loading axis, shown in Figure 3b, which determined that there was regions within the high porosity AM SS specimen that have measured porosity as high as $\sim 17 \%$, while the other sample, low porosity AM SS, has a maximum porosity of less than $2 \%$. Also, there was a distinct difference in the shape of the pores. For the high porosity specimens the defects were highly irregular and had pointed features, as shown in Figure 4. Also observed within an elongated pore in Figure 4 are un-melted and loosely bonded powder particles. This has been observed previously in the literature [5]. 


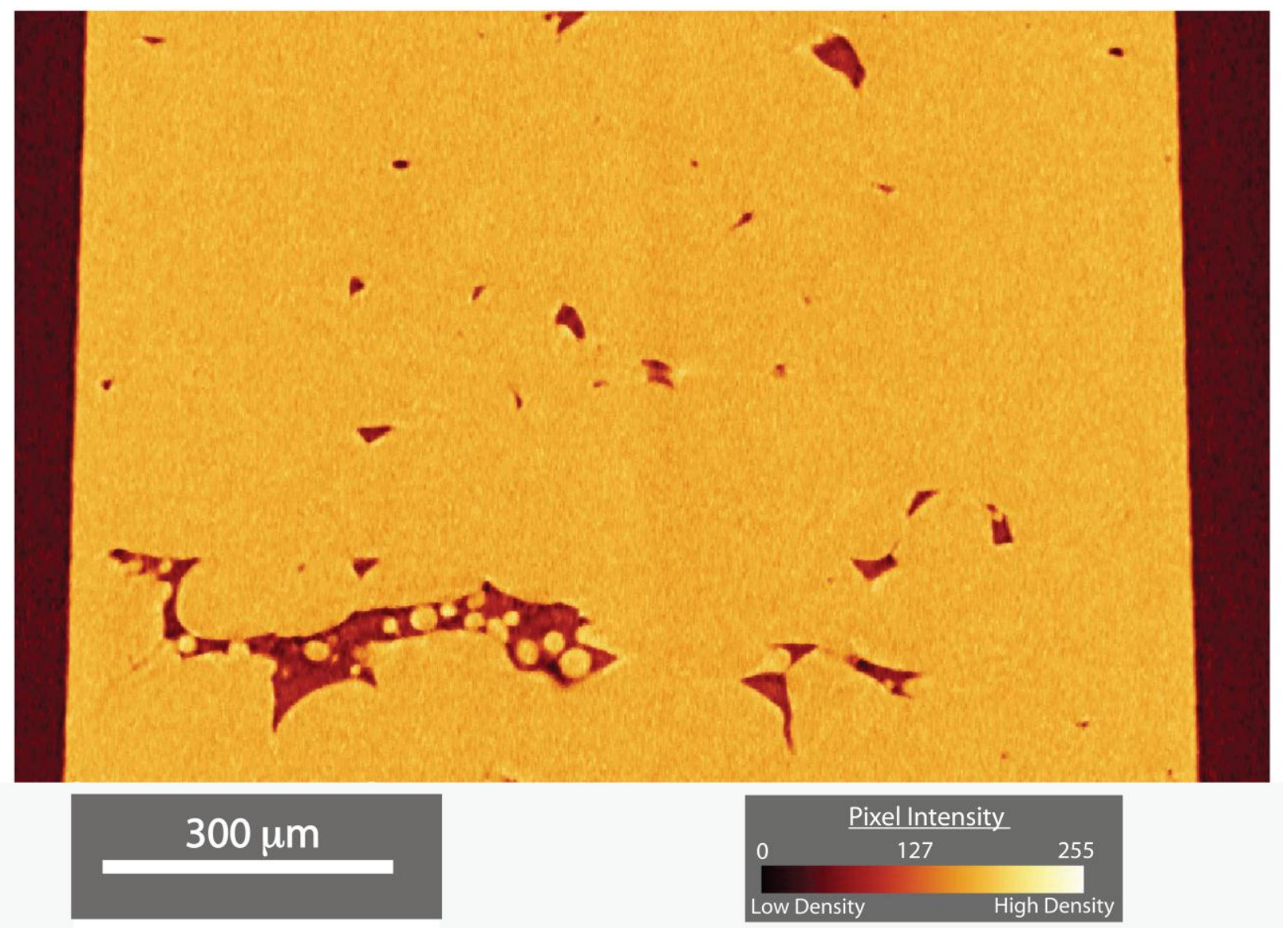

Figure 4. Defects found in high porosity SS specimen. Tomographic image taken during deformation of the high porosity SS AM sample group built with $100 \mathrm{~W}$ power and $400 \mathrm{~mm} / \mathrm{s}$ speed and tested in the as-built condition. The orange represents the stainless steel material matrix as shown by the colormap, which represents the pixel intensity. The lighter shades in the image represent regions with higher density material. Within the matrix there are noticeable regions where loosely bonded and unmelted powder sit within pores. Also the pores have a jagged shape with sharp corners protruding into the matrix. 
Pore analysis was performed on a wrought SS specimen. Figure 5 shows the 3D rendering of the evolution of defects, most likely pores, within a $500 \times 500 \times 500 \mu \mathrm{m}^{3}$ volume, for a wrought specimen under no load and then captured right before fracture, which corresponds to a stress of $510 \mathrm{MPa}$. Figure 5a shows two surface renderings of the sample under different loading conditions, 0 and $510 \mathrm{MPa}$. In Figure $5 \mathrm{~d}$ the defect distribution was quantified for the wrought specimen prior to loading for a cropped volume of $500 \times 500 \times 1300 \mu \mathrm{m}^{3}$. In this sample volume there were 26 small pores detected and the largest pore size was measured at $2000 \mu \mathrm{m}^{3}$. For a representative low porosity specimen the largest detected pore was measured to be $4.0 \times 10^{4} \mu \mathrm{m}^{3}$, while for a representative high porosity specimen the largest pore volume was measured at $1100.0 \times 10^{4} \mu \mathrm{m}^{3}$. Figure $5 \mathrm{~b} \& \mathrm{c}$ show the evolution of the small spherical voids in the wrought specimen, which appeared to elongate along the orientation of the applied load within the center of the specimen during deformation. 


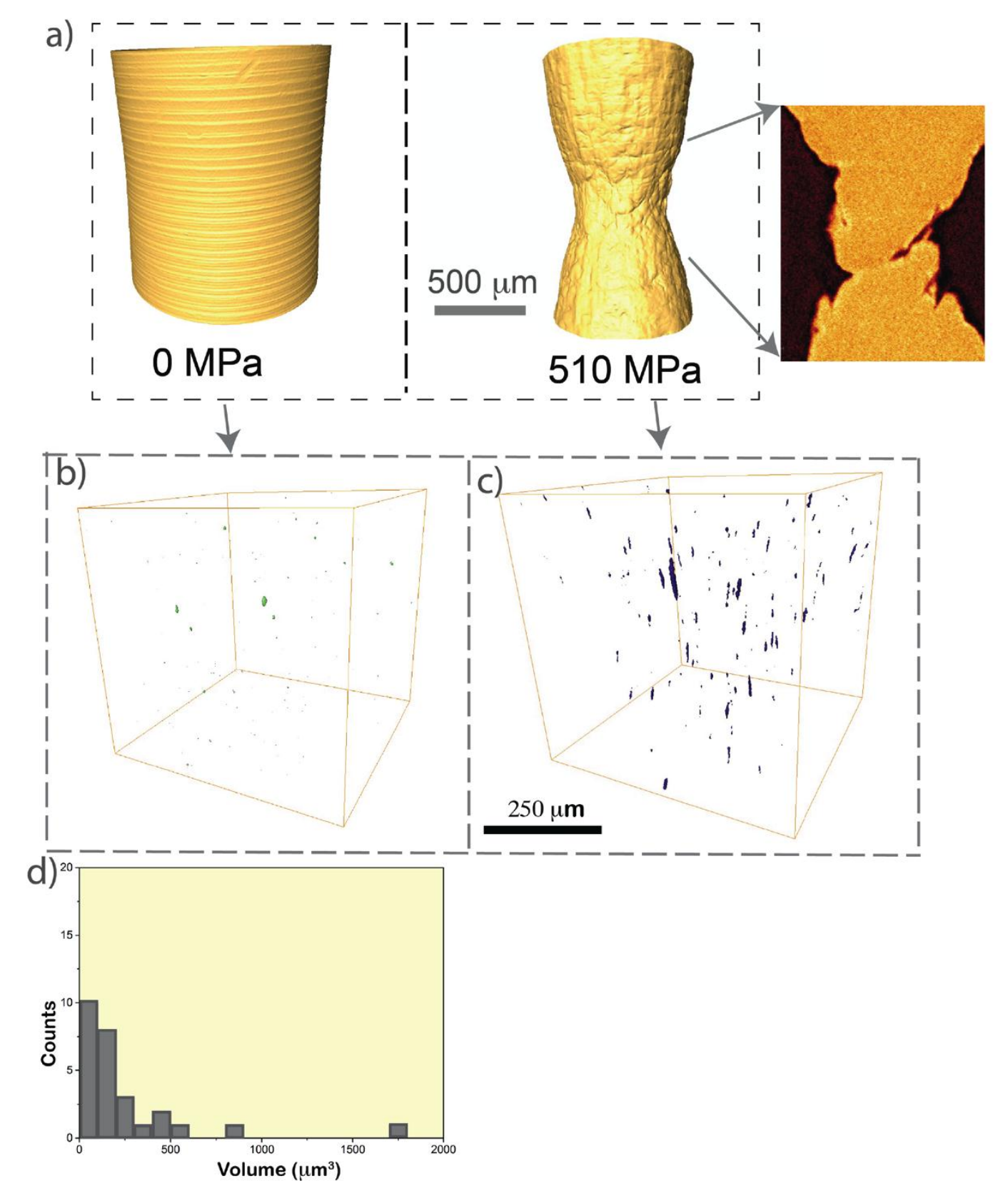

Figure 5. Wrought SS results. a) Surface rendering of a wrought SS specimen under a tensile stress of $0 \mathrm{MPa}$ (left) and $510 \mathrm{MPa}$ (right) taken from tomography data. Image to the right of the $510 \mathrm{MPa}$ loaded sample shows a 2-dimensional (2D) slice through the deformed wrought specimen displaying cracks. Images b) and c) show 3D rendering of defects segmented out of a $(500 \mu \mathrm{m})^{3}$ volume. The largest defect was measured to have a volume of $5714 \mu \mathrm{m}^{3}$, while the largest defect under no stress was $817 \mu \mathrm{m}^{3}$. (d) Plot 
showing the distribution of voids segmented out of a $500 \times 500 \times 1300 \mu \mathrm{m}^{3}$ region of a wrought SS 316L specimen prior to loading.

Figure 6 shows the tomography images from an in situ tensile test performed on a representative annealed AM SS specimen with low porosity. The results from this test are summarized in Table 3. The images shown in 6 follow the damage evolution of the sample from an unloaded state to an imposed engineering stress of $550 \mathrm{MPa}$, which captures the sample right before fracture. Table 3 shows the change in the RA and porosity that occurred right before failure. It was determined that the largest void present in the specimen approximately doubled in volume during loading to failure.

Table 3. Results from the in situ tensile testing performed on an AM (annealed) SS specimen shown in Fig. 6. 


\begin{tabular}{|lcc|}
\hline Data set taken: & $\begin{array}{c}\text { Prior to } \\
\text { loading }\end{array}$ & $\begin{array}{c}\text { Right } \\
\text { before } \\
\text { failure }\end{array}$ \\
\hline Reduction of Area (\%) & 0 & 78 \\
\hline Engineering Stress during scan $(\mathbf{M P a})$ & 0 & 550 \\
\hline Average Void Volume $\left(\mu \mathbf{m}^{3}\right)$ & 1460 & 1760 \\
\hline Median Void Volume $\left(\mu \mathbf{m}^{3}\right)$ & 240 & 210 \\
\hline Standard Deviation $\left(\mu \mathbf{m}^{3}\right)$ & 4270 & 7440 \\
\hline Largest Void $\left(x 10^{4} \mu \mathbf{m}^{3}\right)$ & 4 & 8.4 \\
\hline Detected Voids $(\#)$ \\
$\left(\right.$ Minimum detected void volume $\left.=34 \mu \mathbf{m}^{3}\right)$
\end{tabular}




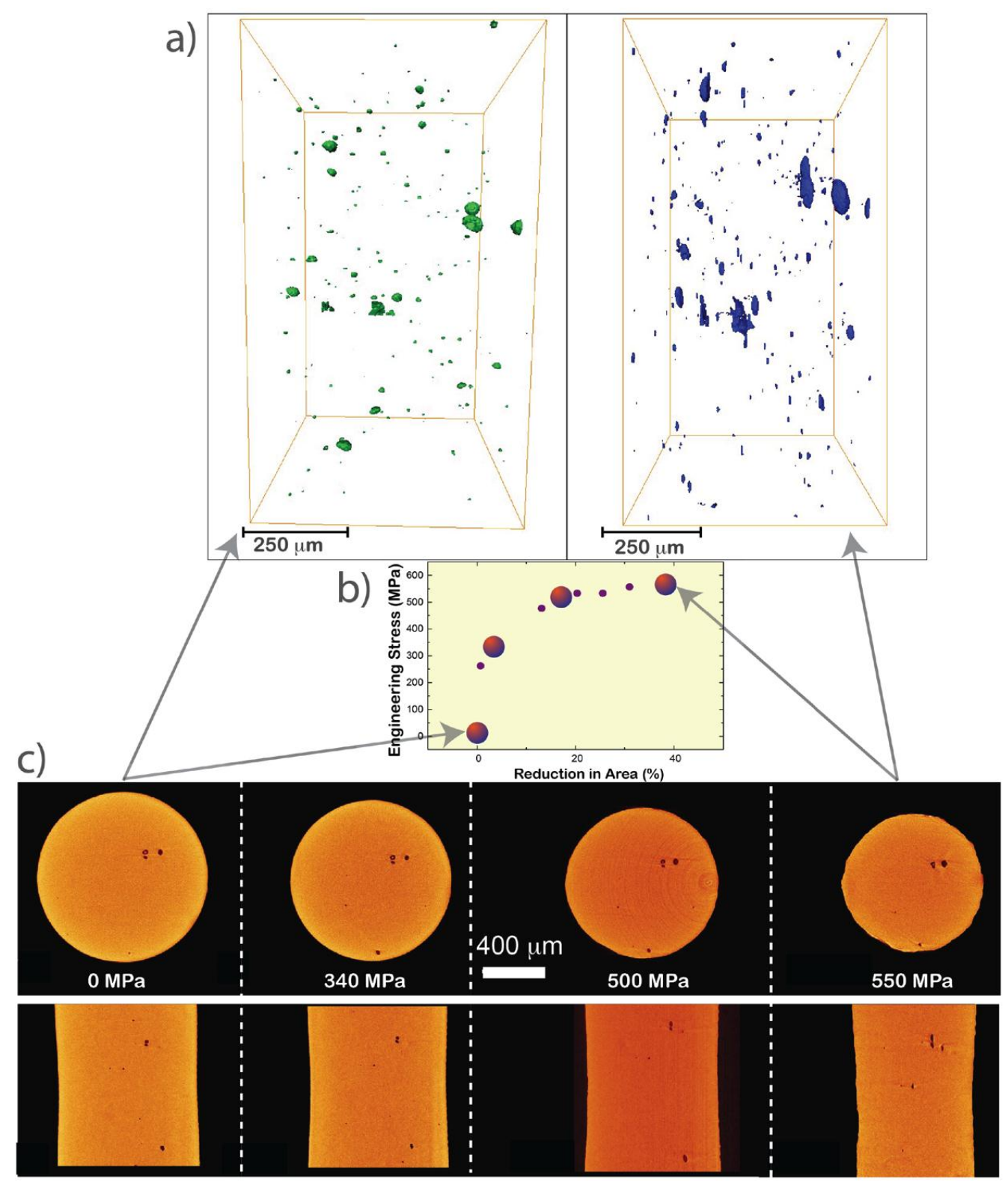

Figure 6. Results from a representative low porosity SS (annealed) specimen. a) 3D mapping of void distribution evolution over time for an AM SS built with $100 \mathrm{~W}$ power and $222 \mathrm{~mm} / \mathrm{s}$ speed. a) The image on the left is the void distribution before mechanical testing and the image to the right is the void distribution captured right before catastrophic failure. The overall porosity was measured at $0.1 \%$ at $0 \mathrm{MPa}$ (left image) and $0.18 \%$ at $550 \mathrm{MPa}$ (right image). b) Shows the engineering stress versus reduction in area for this specimen. c) Shows the 2D slices in two different orientations (cross section and longitudinal section) for this specimen at different stresses and reduction of area values. 
Figure 7 shows the void evolution for a high porosity SS specimen. The overall average porosity increased from $2.2 \%$ at $0 \mathrm{MPa}$ to $5.3 \%$ at $~ 500 \mathrm{MPa}$. Also shown in Figure $7 \mathrm{~b}$ is the existence of crack bridging; it is evident here that the failure in the high porosity specimen was highly defect driven. Also there was significantly less necking in the high porosity group than seen in the low porosity group and some of the specimens showed bifurcating cracks which originated at irregularly shaped pores throughout the height of the specimens. Movie 1 shows a set of tomographic slices through a high porosity specimen under load and a 3D volumetric rendering of the pore distribution within the specimen. 
a)

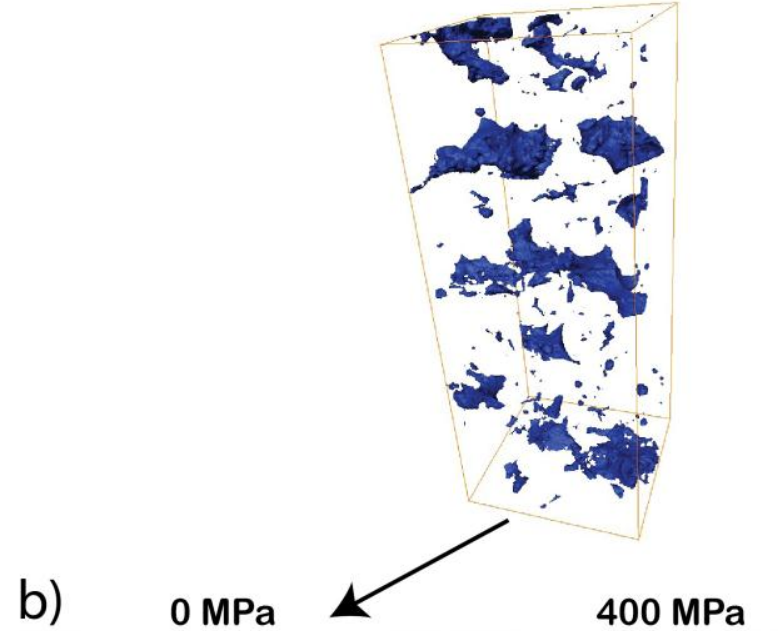

Average porosity: $5.3 \%$

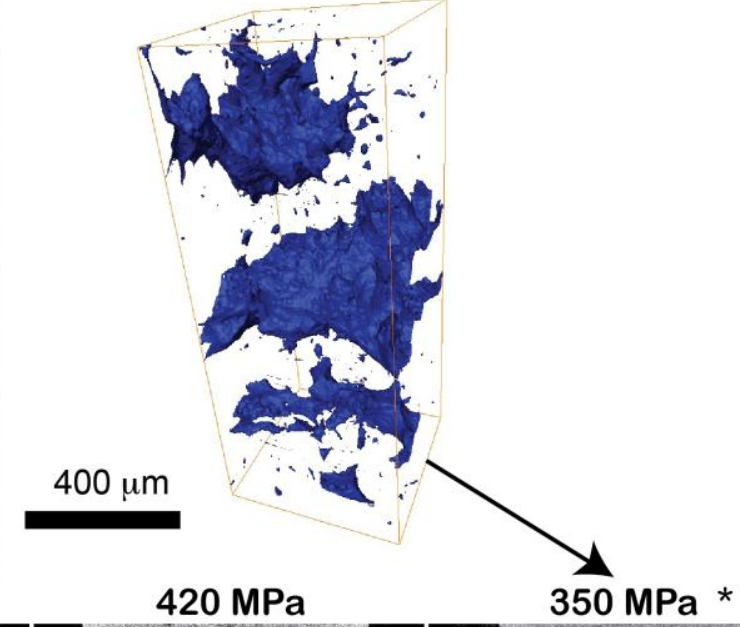

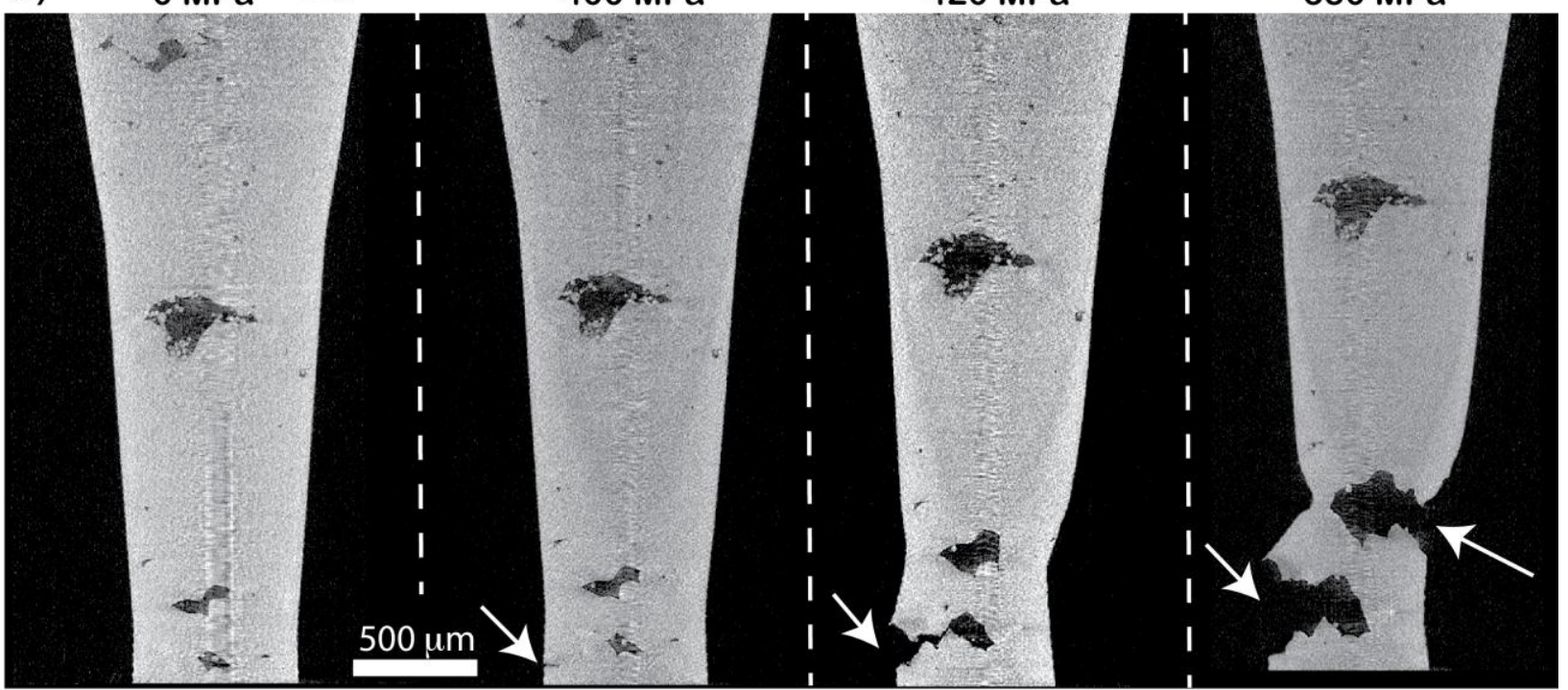

Figure 7. Results from a high porosity SS specimen. (a) 3D rendering of the segmented void distribution for an AM high porosity (100 W, $400 \mathrm{~mm} / \mathrm{s})$ SS sample before mechanical testing (left) and right before failure catastrophically (right). Tomographic images (b) captured at different load and displacements during tensile loading. Crack bridging is observed between existing voids in this high porosity tensile specimen as pointed out by the white arrows. Although it appears that there is a reduction in area, this is mainly due to the tapered geometry of the tensile specimen and the slice angle view. 
Engineering stress versus RA plots taken from in situ tensile testing data are shown in Figure 8 and the mechanical properties are summarized in Table 4 . The wrought and AM annealed low porosity SS group both displayed high amounts of ductility and were both identified as possessing less than $0.1 \%$ porosity with homogenous porosity distribution. Although the as-built specimens had a higher ultimate tensile strength, which is related to the different microstructure of the as-built SS, the mechanical properties were observed to be much more unpredictable. The standard deviation for the mechanical properties was much higher for AM SS due to the large variation in porosity distributions between specimens, even between samples in the same group. 

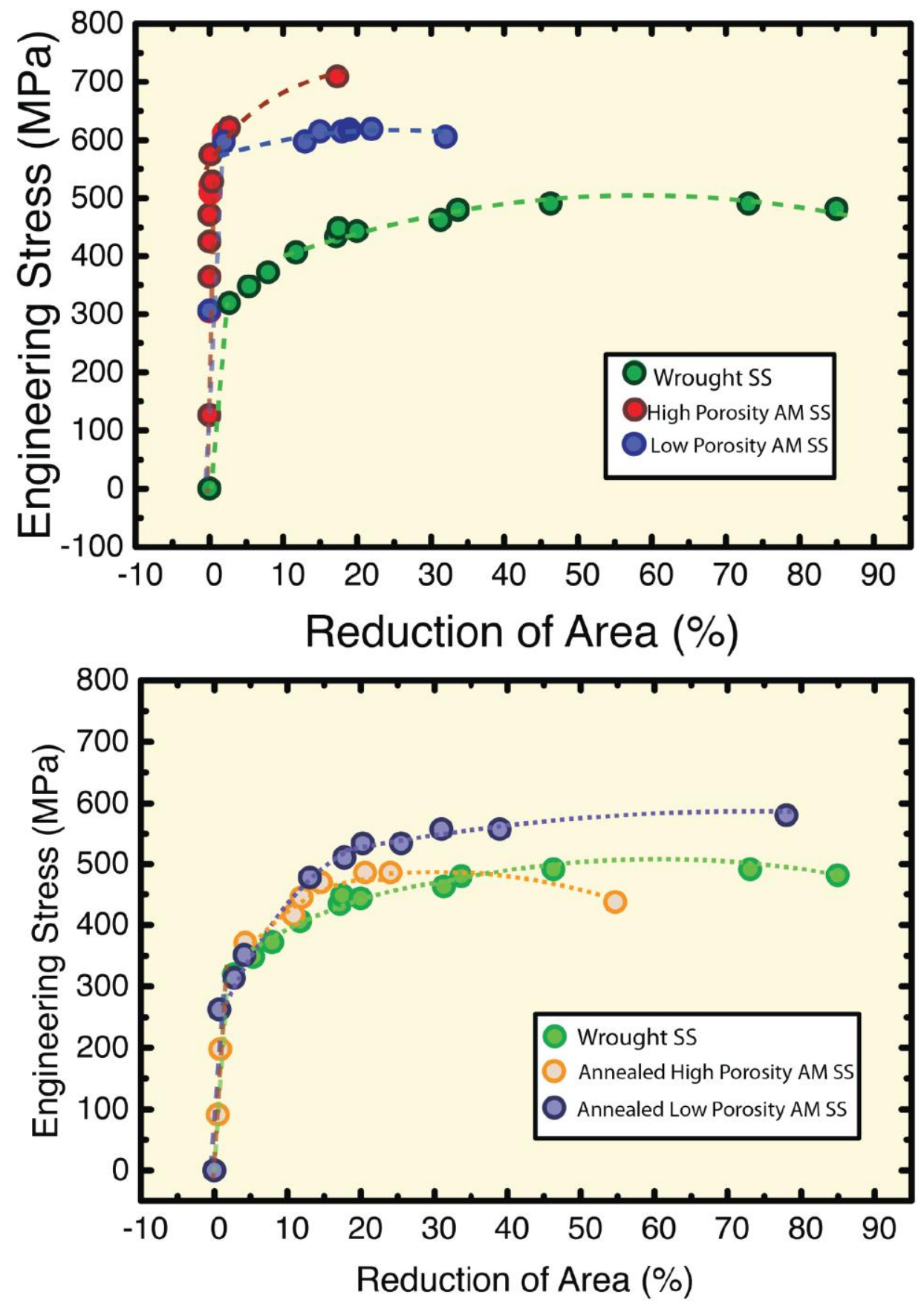

Figure 8. Results from in situ tensile tests. Engineering stress versus reduction of area for the wrought versus as-built and the wrought versus annealed samples. 
The fractured specimen's side profile, as shown in Figure 9, was evaluated with respect to final reduction of area and fracture behavior. The wrought SS displayed an 85\% RA, which was similar to the RA measured in the annealed AM SS specimens with low porosity (75\% RA), while AM as-built SS specimens with high porosity had an average of $\sim 30 \%$ RA. The images in Figure 9a show the necking and a cup-cone failure behavior in the low porosity annealed and wrought SS specimens, as compared to the flat-like side profile of the as-built fracture. Also the as-built specimen, Figure $9 \mathrm{~b}$, clearly shows the presence of melt pool boundaries and pores on the fracture surface.

Fractography was performed, using a scanning electron microscope (SEM), to further assess the failure behavior of each group. Several fracture surfaces for AM SS specimens are shown in Figure 10. There was a large presence of pores/voids observed on the asbuilt specimen's fracture surface and these defects could have acted as initiation sites for crack bridging shown in the tomography imaging (Figure 7). Also prevalent on the fracture surface of the as-built high porosity AM SS specimen was a large amount of unmelted powder particles. As expected, the wrought SS fracture surface shows a dimple morphology indicating nucleation, growth, and coalescence as part of a ductile fracture mode. The annealed low porosity SS specimen's fracture surface also shows ductile dimples but with a finer microstructure. Both the tomography and the fractography 
showed that the necking region was much more asymmetric for the as-built AM SS, which appear to be more of an oval, indicating that localized variations in the mechanical behavior exist, especially for AM SS specimens that have been neither stress-relieved or annealed.

Table 4. Summary of mechanical properties, ultimate tensile strength and reduction of area with the subsequent measured porosity, determined from the in situ tensile tests performed on stainless steel. The large standard deviation seen in the AM as-built is a result of the different porosity distributions for the various AM samples.

\begin{tabular}{|c|ccc|}
\hline & UTS & $\begin{array}{c}\text { (Tomography } \\
\text { Results) } \\
\text { Type of SS }\end{array}$ & $\begin{array}{c}\text { Reduction of } \\
\text { Area }\end{array}$ \\
& \multicolumn{3}{|c|}{$\begin{array}{c}\text { Porosity } \\
\mathbf{( \% )}\end{array}$} \\
\hline $\begin{array}{c}\text { Wrought } \\
\text { (n=2) }\end{array}$ & $505+/-20$ & $0.004+/-0.0015$ & $85+/-1$ \\
\hline AM as-built & $630+/-60$ & $0.1+/-0.04$ & $55+/-20$ \\
Low Porosity & & & \\
(n=3) & & & \\
\hline AM Annealed & 555 & & \\
Low Porosity & & & \\
\hline
\end{tabular}




\begin{tabular}{|c|c|c|c|}
\hline$(\mathrm{n}=1)$ & & & \\
\hline $\begin{array}{l}\text { AM as-built } \\
\text { High Porosity } \\
\qquad(n=3)\end{array}$ & $540+/-120$ & $2.4+/-0.7$ & $30+/-15$ \\
\hline $\begin{array}{l}\text { AM Annealed } \\
\text { High Porosity } \\
\qquad(\mathrm{n}=1)\end{array}$ & 490 & 2.2 & 55 \\
\hline
\end{tabular}

Along with porosity, microstructure plays a large role in affecting the mechanical properties of SS. Figure 11 shows micrographs comparing the as-built and annealed microstructures where there is a noticeable difference, specifically in the as-built condition where there is a dendritic fine columnar microstructure [30] found within the grains. The microstructures also differ from wrought, which can be attributed to the high cooling rate and rapid solidification imposed by the SLM process. Similar microstructures have been reported in the literature for AM 316L SS [31, 32]. Also observed in the material and on the fracture surfaces of the as-built SS are prominent melt pool boundaries that overlap with the grain structure. 


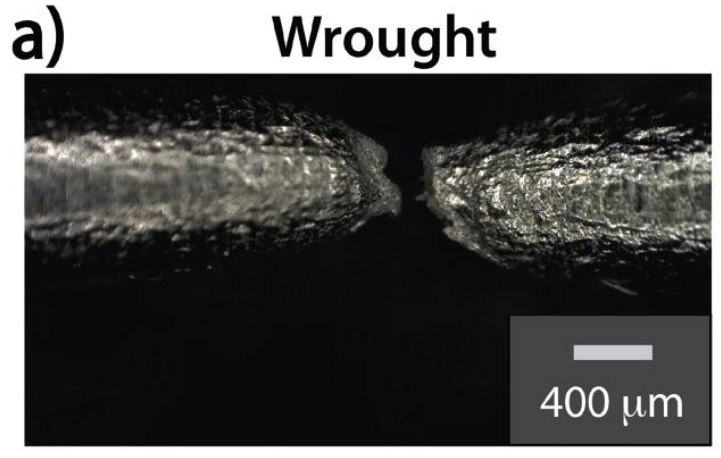

\section{AM Low Porosity Annealed}

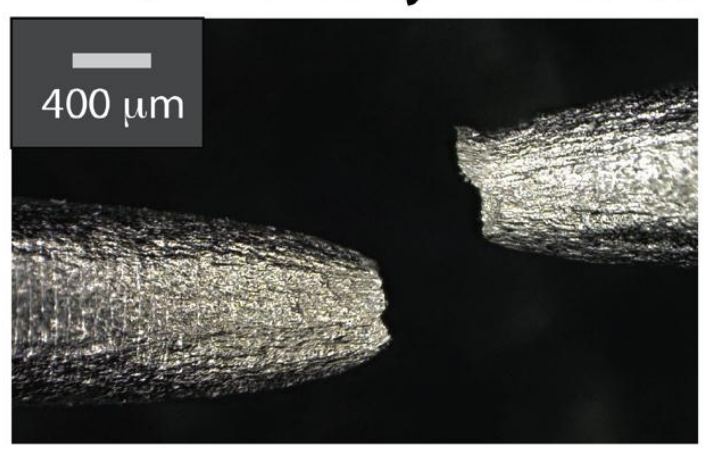

AM SS High Porosity

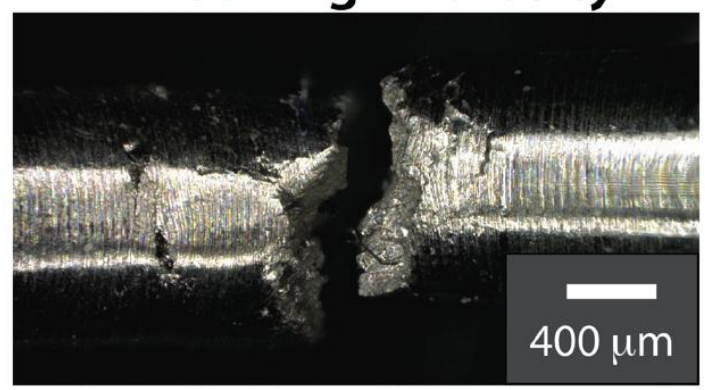

b)

Fracture Surface

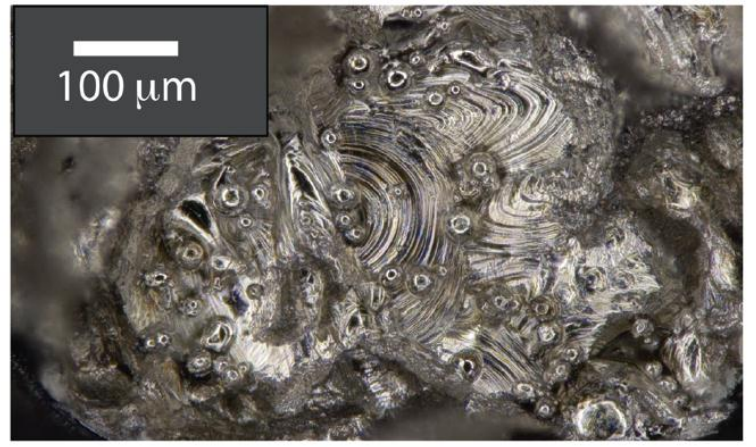

Figure 9. Fracture Behavior of SS. Images showing side views of the fractured in situ tensile specimen for the high and low porosity groups built using SLM with a power of $100 \mathrm{~W}$ and speed of 400 and $222 \mathrm{~mm} / \mathrm{s}$, respectively. There are visible differences in the fracture behavior between the AM SS specimen with low and high porosity. Image b) shows the fracture surface where the melt pool boundaries are evident on the as-built AM SS specimen.

\section{Conclusions}

Careful control of the SLM process must be implemented with regard to build parameters and post-processing heat treatments. These parameters and heat treatments are selected based on each metal part's application, and are highly material specific. For 
this study the deformation and failure behavior of AM SLM 316L SS was investigated in the as-built and annealed conditions and compared to wrought SS. A parametric study of the SLM process would include more than 130 parameters with various combinations of the parameters, which could result in a wide range of porosity, as well as porosity morphology and distribution. The AM parameter sets studied here (100 W laser power, $0.7 \mathrm{a} 1,30 \mu \mathrm{m}$ layer thickness, and two scan speeds, 222 and $400 \mathrm{~mm} / \mathrm{s}$ ) showed that the AM SS specimens built with the higher speed produced a part faster but showed an increase in porosity. The slower speed parameter set had lower porosity, although still higher than wrought material, and improved mechanical properties, and when properly heat treated showed mechanical properties which compared to the wrought material. Specifically, annealing the as-built material decreased the yield strength, but increased the ductility of the AM SS.

This study demonstrated that the SLM process produces metals with a range of porosity distributions and pore morphologies. It was shown here that, rather than just bulk density, pore size and morphology are extremely important when assessing an AM metal's mechanical properties. Overall, AM SS built with low porosity displayed fracture mechanisms similar to wrought specimen, while AM SS built with a 
heterogeneous pore distribution, varying between 0 and $17 \%$ porosity, displayed a flaw driven failure.

a) Annealed Low Porosity AM SS



b) High Porosity AM SS

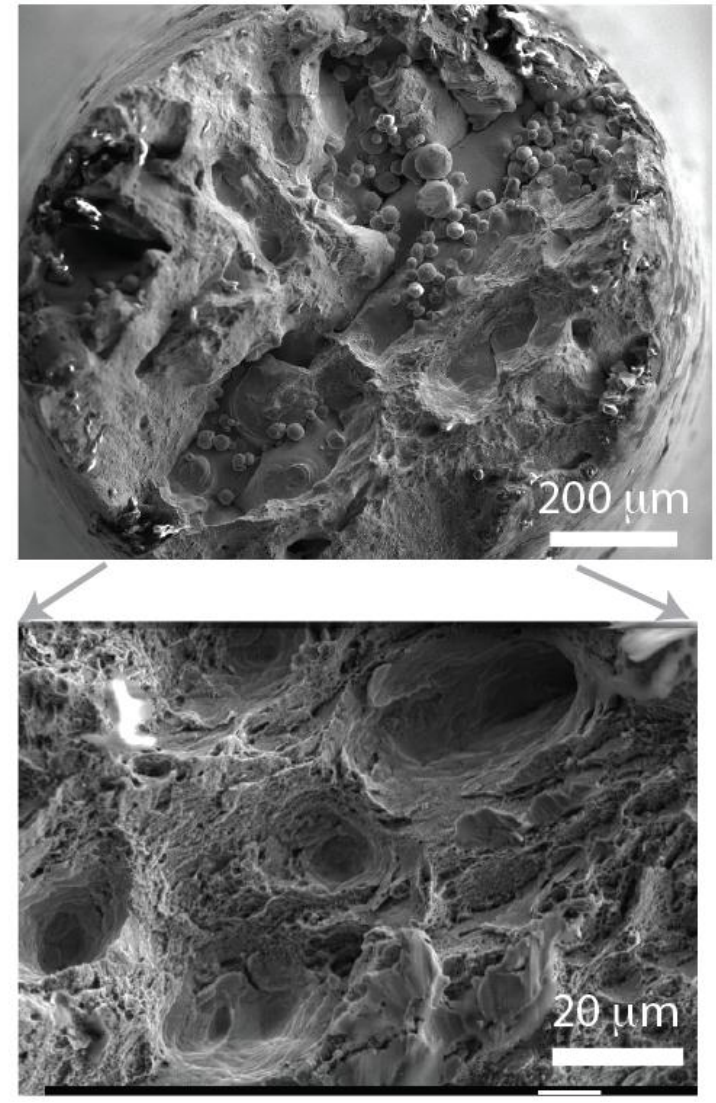

Figure 10. Fractography of AM SS specimens. SEM images showing the fracture surface of an a) annealed low porosity (100 W, $222 \mathrm{~mm} / \mathrm{s})$ and an b) as-built high porosity $(100 \mathrm{~W}, 400 \mathrm{~mm} / \mathrm{s})$ specimen. 

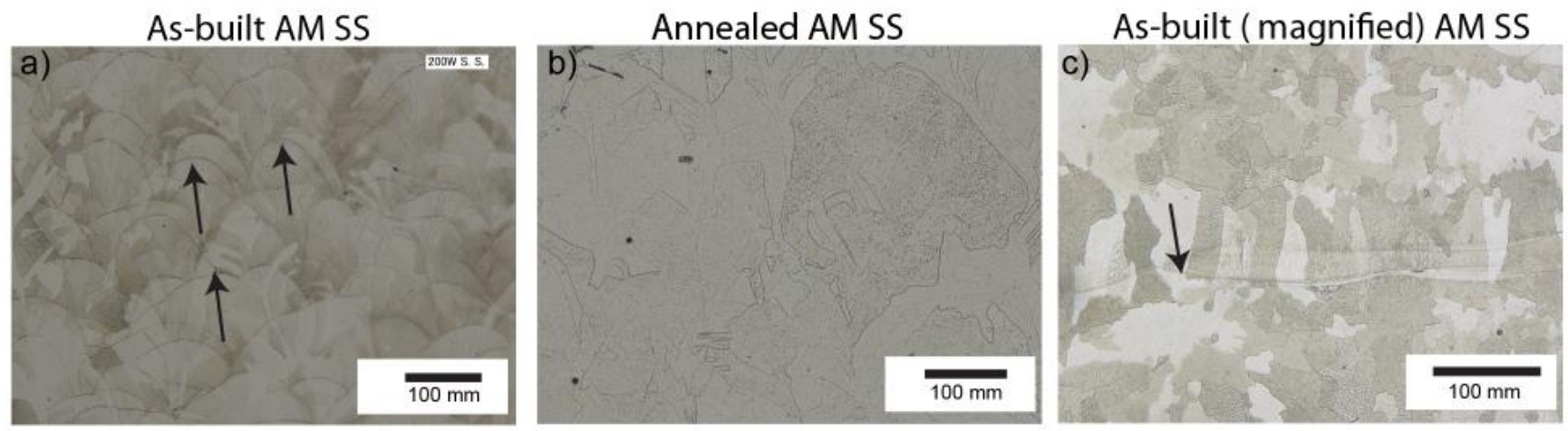

Figure 11. Microstructural observations of AM SS. Micrographs showing the microstructure of the a) as-built and b) annealed AM 316L SS. Image c) shows a higher magnification optical micrograph of the as-built specimen showing the dendritic structure inside the grain boundaries. The black arrows point to melt pool boundaries. 


\section{Acknowledgements}

We would like to acknowledge LLNL's Accelerated Certification of Additively Manufactured Metals (ACAMM) strategic initiative leader, Wayne King, for funding and encouraging this work. We would also like to acknowledge Ray Swan for providing the designs for the modified base of the test rig. This work was performed under the auspices of the U.S. Department of Energy by Lawrence Livermore National Laboratory under Contract DE-AC52-07NA27344. This work was funded by the Laboratory Directed Research and Development Program at LLNL under project tracking code 13-SI-002. The Advanced Light Source is supported by the Director, Office of Science, Office of Basic Energy Sciences, of the U.S. Department of Energy under Contract No. DE-AC02-05CH11231. 


\section{References}

[1] M. Vaezi, H. Seitz, S. Yang. A review on 3D micro-additive manufacturing technologies, Int J Adv Manuf Technol (2012) 1-34.

[2] W.E. King, H.D. Barth, V.M. Castillo, G.F. Gallegos, J.W. Gibbs, D.E. Hahn, C. Kamath, A.M. Rubenchik. Observation of keyhole-mode laser melting in laser powder-bed fusion additive manufacturing, Journal of Materials Processing Technology 214 (2014) 29152925.

[3] C. Kamath, B. El-dasher, G. Gallegos, W. King, A. Sisto. Density of additivelymanufactured, 316L SS parts using laser powder-bed fusion at powers up to $400 \mathrm{~W}$, Int J Adv Manuf Technol (2014) 1-14.

[4] E. Yasa. Manufacturing by Combining Selective Laser Melting and Selective Laser Erosion / Laser Re- Melting. Faculty of Engineering, Department of Mechanical Engineering, vol. Ph.D. Heverlee (Leuven): Katholieke Universiteit Leuven, 2011. 
[5] B. Song, S.J. Dong, S.H. Deng, H.L. Liao, C. Coddet. Microstructure and tensile properties of iron parts fabricated by selective laser melting, Optics and Laser Technology 56 (2014) 451-460.

[6] S. Dadbakhsh, L. Hao, N. Sewell. Effect of selective laser melting layout on the quality of stainless steel parts, Rapid Prototyping Journal 18 (2012) 241-249.

[7] R. Li, Y. Shi, Z. Wang, L. Wang, J. Liu, W. Jiang. Densification behavior of gas and water atomized 316L stainless steel powder during selective laser melting, Applied Surface Science 256 (2010) 4350-4356.

[8] M. Rombouts, J.P. Kruth, L. Froyen, P. Mercelis. Fundamentals of Selective Laser Melting of alloyed steel powders, CIRP Annals - Manufacturing Technology 55 (2006) 187192.

[9] M.S.F. de Lima, S. Sankaré. Microstructure and mechanical behavior of laser additive manufactured AISI 316 stainless steel stringers, Materials \& Design 55 (2014) 526-532.

[10] I. Tolosa, F. Garciandia, F. Zubiri, F. Zapirain, A. Esnaola. Study of mechanical properties of AISI 316 stainless steel processed by "selective laser melting", following different manufacturing strategies, International Journal of Advanced Manufacturing Technology 51 (2010) 639-647.

[11] B. Zhang, L. Dembinski, C. Coddet. The study of the laser parameters and environment variables effect on mechanical properties of high compact parts elaborated by selective laser melting 316L powder, Materials Science and Engineering: A 584 (2013) 2131.

[12] B. Verlee, T. Dormal, J. Lecomte-Beckers. Density and porosity control of sintered 316L stainless steel parts produced by additive manufacturing, Powder Metallurgy 55 (2012) 260-267.

[13] L. Wang, P. Pratt, S.D. Felicelli, H. El Kadiri, J.T. Berry, P.T. Wang, M.F. Horstemeyer, Tms. Experimental Analysis of Porosity Formation in Laser-Assisted Powder Deposition Process, Minerals, Metals \& Materials Soc, Warrendale, 2009.

[14] P. Rochus, J.Y. Plesseria, M. Van Elsen, J.P. Kruth, R. Carrus, T. Dormal. New applications of rapid prototyping and rapid manufacturing (RP/RM) technologies for space instrumentation, Acta Astronautica 61 (2007) 352-359.

[15] B. Gorny, T. Niendorf, J. Lackmann, M. Thoene, T. Troester, H.J. Maier. In situ characterization of the deformation and failure behavior of non-stochastic porous structures processed by selective laser melting, Materials Science and Engineering: A 528 (2011) 7962-7967. 
[16] I. Yadroitsev, I. Shishkovsky, P. Bertrand, I. Smurov. Manufacturing of finestructured 3D porous filter elements by selective laser melting, Applied Surface Science 255 (2009) 5523-5527.

[17] M.N. Ahsan, C.P. Paul, L.M. Kukreja, A.J. Pinkerton. Porous structures fabrication by continuous and pulsed laser metal deposition for biomedical applications; modelling and experimental investigation, Journal of Materials Processing Technology 211 (2011) 602609.

[18] L. Lecarme, E. Maire, A. Kumar K.C, C. De Vleeschouwer, L. Jacques, A. Simar, T. Pardoen. Heterogenous void growth revealed by in situ 3-D X-ray microtomography using automatic cavity tracking, Acta Materialia 63 (2014) 130-139.

[19] C. Landron, E. Maire, O. Bouaziz, J. Adrien, L. Lecarme, A. Bareggi. Validation of void growth models using X-ray microtomography characterization of damage in dual phase steels, Acta Materialia 59 (2011) 7564-7573.

[20] E. Maire, O. Bouaziz, M. Di Michiel, C. Verdu. Initiation and growth of damage in a dual-phase steel observed by X-ray microtomography, Acta Materialia 56 (2008) 49544964.

[21] A. Haboub, H.A. Bale, J.R. Nasiatka, B.N. Cox, D.B. Marshall, R.O. Ritchie, A.A. MacDowell. Tensile testing of materials at high temperatures above $1700^{\circ} \mathrm{C}$ with in situ synchrotron X-ray micro-tomography, Rev. Sci. Instrum. 85 (2014) 083702.

[22] H.A. Bale, A. Haboub, A.A. MacDowell, J.R. Nasiatka, D.Y. Parkinson, B.N. Cox, D.B. Marshall, R.O. Ritchie. Real-time quantitative imaging of failure events in materials under load at temperatures above $1,600^{\circ} \mathrm{C}$, Nat Mater 12 (2013) 40-46.

[23] J.-P. Kruth, J. Deckers, E. Yasa, R. Wauthlé. Assessing influencing factors of residual stresses in Selective Laser Melting using a novel analysis method. Proc. 16th International Symposium on Electromachining (ISEM XVI). Shanghai, China, 2010. p.pp. 531-540.

[24] M. Stampanoni, R. Mokso, F. Marone, J. Vila-Comamala, S. Gorelick, P. Trtik, K. Jefimovs, C. David. Phase-contrast tomography at the nanoscale using hard $\mathrm{x}$ rays, Physical Review B 81 (2010) 140105.

[25] Metals Handbook, Volume 4 - Heat Treating. 9th Edition., American Society for Metals (1981).

[26] J.H. Kinney, M.C. Nichols. X-Ray Tomographic Microscopy (XTM) Using Synchrotron Radiation, Annual Review of Materials Science 22 (1992) 121-152.

[27] D.M. Vlassenbroeck J, Masschaele B, Cnudde V, Van Hoorebeke L, Jacob P. Software tools for quantification of x-ray microtomography at the 'Center for X-ray Tomography' at Ghent University. Nucl Instru Meth Physics Res A 2007. p.442-445. 
[28] Avizo $^{\text {TM }}$ 3D visualization framework. Chelmsford, MA.: Mercury CS, 2008.

[29] A. Wu, D. Brown, M. Kumar, G. Gallegos, W. King. An Experimental Investigation into Additive Manufacturing-Induced Residual Stresses in 316L Stainless Steel, Metallurgical and Materials Transactions A 45 (2014) 6260-6270.

[30] K. Saeidi, X. Gao, Y. Zhong, Z.J. Shen. Hardened austenite steel with columnar subgrain structure formed by laser melting, Materials Science and Engineering: A 625 (2015) 221-229.

[31] E. Yasa, J.P. Kruth. Microstructural investigation of Selective Laser Melting 316L stainless steel parts exposed to laser re-melting, Procedia Engineering 19 (2011) 389-395.

[32] J.A. Cherry, H.M. Davies, S. Mehmood, N.P. Lavery, S.G.R. Brown, J. Sienz. Investigation into the effect of process parameters on microstructural and physical properties of 316L stainless steel parts by selective laser melting, Int J Adv Manuf Technol 76 (2015) 869-879. 